\title{
Article \\ Statistical Assessment of Electric Shock Hazard in MV Electrical Power Substations Supplied from Networks with Non-Effectively Earthed Neutral Point
}

\author{
Rafał Tarko*(D), Jarosław Kmak, Wiesław Nowak (D) and Waldemar Szpyra (D)
}

Citation: Tarko, R.; Kmak, J.; Nowak, W.; Szpyra, W. Statistical Assessment of Electric Shock Hazard in MV Electrical Power Substations Supplied from Networks with Non-Effectively Earthed Neutral Point. Energies 2022, 15, 1560 . https://doi.org/10.3390/en15041560 Academic Editor: Abu-Siada Ahmed

Received: 28 December 2021 Accepted: 18 February 2022 Published: 20 February 2022

Publisher's Note: MDPI stays neutral with regard to jurisdictional claims in published maps and institutional affiliations.

Copyright: (C) 2022 by the authors. Licensee MDPI, Basel, Switzerland. This article is an open access article distributed under the terms and conditions of the Creative Commons Attribution (CC BY) license (https:// creativecommons.org/licenses/by/ $4.0 /)$.
Department of Electrical Engineering and Power Engineering, Faculty of Electrical Engineering, Automatics, Computer Science and Biomedical Engineering, AGH University of Science and Technology, al. Mickiewicza 30, 30-059 Krakow, Poland; jaroslaw.kmak@agh.edu.pl (J.K.); wieslaw.nowak@agh.edu.pl (W.N.); wszpyra@agh.edu.pl (W.S.)

* Correspondence: rtarko@agh.edu.pl; Tel.: +48-126-173-653

\begin{abstract}
This paper focuses on the evaluation of the electric shock hazard accompanying earth faults in a non-effectively earthed medium-voltage (MV) electrical power network. This hazard depends on the duration and value of the fault current. While the fault current depends on several factors, the most important is the neutral point earthing method. The value of the fault current affects the earthing-electrode voltage value, being the basis for the assessment of electric shock hazard in MV/LV substations. The earthing-electrode voltage is also influenced by the resistance of the substation earthing, which in practice is random. Therefore, an original statistical evaluation method for assessing the electric shock hazard has been developed and presented in this paper. It is based on a statistical model of the MV/LV substation earthing resistance, worked out on the basis of experiments and measurements in real electrical power networks. This method can be used for the determination of statistical distributions of earthing-conductor voltages in real electrical power networks, and on this basis, the MV/LV substations with rates of electric shock hazard that are too high can be indicated. This also makes it possible to determine the longest permissible fault current interruption times or the highest permissible earthing resistances for specific substations. This method is also applicable when selecting the neutral point earthing method. The developed method was used in all of the above proposed areas by performing calculations on a model of a real $15 \mathrm{kV}$ network with the neutral point earthed by a resistor. This analysis proves the practicability of the method both at the stage of designing power networks, and when a change in the neutral point earthing method in existing networks is being considered. Particularly valuable is also the statistical model of an earthing electrode resistance, developed on the basis of measurements in $2408 \mathrm{MV} / \mathrm{LV}$ substations, which may also be applicable in the future studies.
\end{abstract}

Keywords: medium-voltage networks; neutral earthing; medium/low voltage substation; earthingelectrode voltage; electric shock hazard; statistical assessment

\section{Introduction}

The method used for neutral point earthing in electrical power networks significantly determines their design and operation. The values of earth fault currents, which have a direct impact on the electric shock hazard, overvoltage level, and reliability of the protection control system [1], depend on this method. Therefore, the choice of the method used for neutral point earthing is a complex issue with multiple aspects. In practice, several options [2,3] are available, and systems can be classified into two basic groups:

(1) effectively earthed systems;

(2) non-effectively earthed systems.

In the first group, the neutral point has a solid connection with the earthing system, i.e., selected transformer star points are earthed. In the second group, the neutral point is 
impedance-connected with the earthing system, by means of either a resistor, a reactor, or their connection in parallel. A special case is the lack of connection of the neutral point with the earth. Each of the mentioned methods of neutral point connection has its own advantages and disadvantages, which determine the working conditions of the network during phase-to-earth faults.

Medium-voltage (MV) grids most often operate with a non-effectively earthed neutral point (Figure 1).

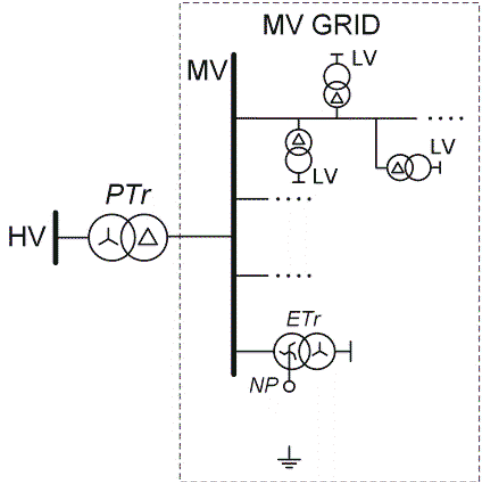

(a)

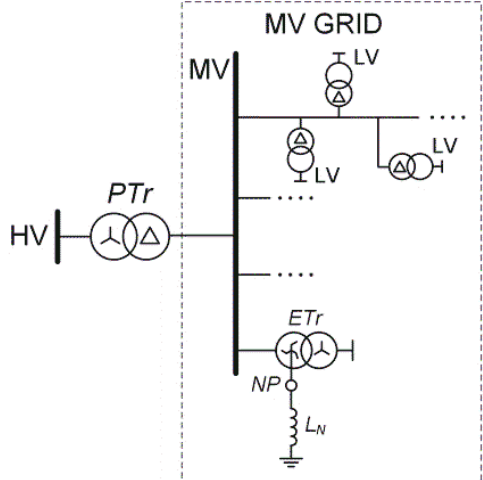

(b)

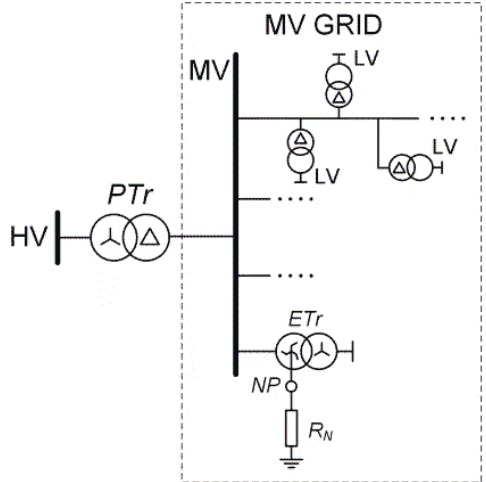

(c)

Figure 1. MV grid with non-effectively earthed system: (a) isolated neutral point; (b) reactor-earthed neutral point; (c) resistance-earthed neutral point. HV—high voltage; MV—-medium-voltage; LVlow voltage; $P T r$ - power transformer; ETr — earthing transformer; $N P$ - neutral point; $L_{N}$ —earthing inductor; $R_{N}$-earthing resistor.

Low values of earth fault currents, and thus low risk of electric shocks, are considered advantageous in MV isolated neutral point networks (Figure 1a). Moreover, when the earth fault current does not exceed several amperes, spontaneous arc extinction of earth faults (without operation of circuit breakers) can be achieved in overhead networks. This, however, is mainly true in overhead lines that are not particularly extensive. In the case of cable networks or cable-overhead networks predominantly employing cable lines, the earth fault current can reach much higher values, thus increasing the risk of electric shock caused by earth fault current. This requires the use of reliable protections to quickly resolve earth faults.

For earth fault current values above which the isolation of the neutral point of the network is no longer advantageous, it may be justified to apply reactor neutral point earthing (Figure 1b) in order to lower the value of the earth fault current by compensating the grid capacitance. Conditions can thus be achieved that are highly favorable for arc selfextinction of earth faults in overhead lines. However, the main disadvantage of this method is the difficulty of ensuring the proper operation of earth fault protection [4,5]. Therefore, the operating conditions of such protections are frequently improved through automatic, short-term shunting of the reactor with a resistor to briefly introduce the active component of the earth fault current with values of several to several dozen amperes. A significant disadvantage of resonant earthed neutral networks is their high values of transient line-toearth overvoltages [6,7]. However, this is also true of networks with an isolated neutral point. The problem of earth fault overvoltages is particularly significant in cable networks, because faults through the intermittent arc do not have the ability to extinguish themselves, and the earth fault current can reach values of up to several hundred amperes.

Earth fault overvoltages can be limited by applying resistance earthing of the neutral point of the network (Figure 1c). An additional advantage of this solution is the high reliability of protection operation [3] and the short fault current interruption times. The main disadvantage of this solution is the high risk of electric shock in the MV/LV substations, which is a result of the high values of earth fault currents. Therefore, the resistance provided by the $R_{N}$ earthing resistor is employed to minimize the electric shock hazard. 
Generally, electric shock hazard depends on the current value and its flow time through the human body [8,9]. However, in practice, the basis for evaluating electric shock hazard in MV/LV substations during earth faults is the earthing-electrode voltage. Figure 2 shows a generalized scheme of a substation supplied by an MV grid (Figure 1). When a phase-to-earth fault occurs on the MV side of the substation, the voltage $U_{E}$ appears in the substation earthing system. The value of $U_{E}$ depends on the fault current $I_{F}$, which is split into $I_{R}, I_{E}$, and $I_{P E N}$ currents in the substation earthing system. The earthing system consists of: substation earthing-electrode with resistance $R_{E}$, protective earth and neutral conductor PEN (in LV network) with equivalent resistance $R_{P E N}$, and earth-return paths in the MV network with equivalent impedance $Z_{R}$.

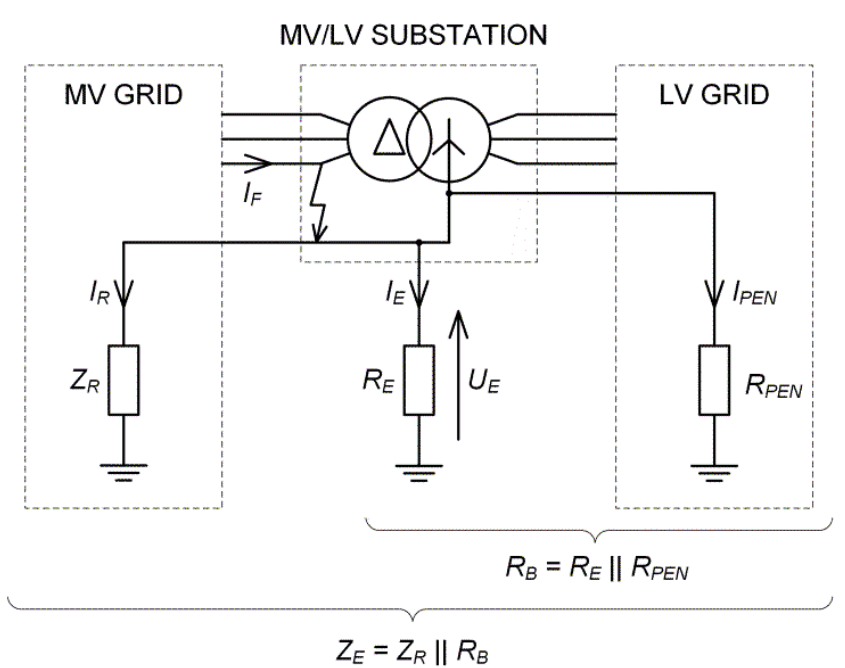

Figure 2. Phase-to-earth fault current flows in the MV/LV substation earthing system: $R_{E}$ - substation earthing-electrode resistance; $R_{P E N}$ - equivalent resistance of protective earth and neutral conductor (PEN) in LV network; $Z_{R}$-impedance of earth-return path in MV network; $I_{F}$ - phase-to-earth fault current; $I_{E}$-earthing current; $U_{E}$ - earthing-electrode voltage.

These issues have been the subject of numerous research works, mainly devoted to the distribution of fault currents in complex earthing systems and to the criteria defining global earthing systems. Among others, [10-12] were devoted to fault current distribution. In [11,12], a sensitivity analysis of the network structure was carried out along with the selection of parameters for the reduction factor. This factor was also the subject of the research presented in [10]; however, in that case, its value in a real medium-voltage network was based on measurements. Low reduction factor values are characteristic of global earthing systems. Despite the development of various methods of determining the area of global earthing systems [13], the development of unambiguous and practicable guidelines presents great difficulties. A separate issue related to electric shock safety in mediumvoltage networks is transferred voltage from $\mathrm{HV} / \mathrm{MV}$ substations during faults in $\mathrm{HV}$ networks, analyzed in $[14,15]$. Substation earthing resistance values were determined deterministically in all of the above-mentioned publications. However, in reality, the equivalent impedance $Z_{E}$ of substation earthing (Figure 2) is not a constant value, as it depends on various random factors. For this reason, the expected value of earthingelectrode voltage $U_{E}$ is also random. This causes the assessment of electric shock hazard to be a problem that is most appropriately solved using a statistical approach [16-18].

The subject of this paper is the statistical evaluation of electric shock hazard in $\mathrm{MV} / \mathrm{LV}$ substations.

The foundations of this evaluation are:

- a statistical model of MV/LV substation earthing resistance developed by the authors based on measurements performed in real grids; and 
- an original method presented by the authors for determining the probability of exceeding the permissible earthing voltage values.

The presented method can be used for determining the statistical distributions of earthing-electrode voltage, and based on these, identifying those MV/LV substations where there is an unacceptable probability of the occurrence of an electric shock hazard. Following this method, the longest permissible fault current interruption times can be determined for these substations, or the maximum earth resistance that ensures that the assumed a priori probability of not exceeding acceptable earthing voltages is met.

The organization of this paper is as follows:

- The analysis of factors affecting the equivalent earthing impedance $Z_{E}$ of MV/LV substations is presented in Section 2. In particular, it is pointed out that this is influenced by deterministic factors related to the earth-return circuit, as well as probabilistic factors stemming from the statistical dispersion of $\mathrm{MV} / \mathrm{LV}$ substation earthing resistance values;

- The method for the statistical evaluation of electric shock hazard at MV/LV substations is presented in Section 3;

- The application of the developed method for the analysis of a real $15 \mathrm{kV}$ network is presented in Section 4. An MV network operating with an isolated neutral point was investigated, in consideration of the possibility of resistance earthing of the neutral point. The calculations made it possible to determine the longest admissible fault current interruption times or the maximum substation earthing resistance after changing the neutral point earthing method.

\section{Analysis of Factors Affecting the Equivalent Impedance to Earth of MV/LV Substations}

The equivalent impedance to earth of a substation $Z_{E}$ is a parallel connection (Figure 2) of equivalent impedance $Z_{R}$ of earth-return paths in the MV network, substation earthingelectrode resistance $R_{E}$, and equivalent resistance $R_{P E N}$ of the protective earth and neutral conductor (PEN) in an LV grid. The values of impedance and resistance, as well as their proportions, have an impact on the fault current flow $I_{F}$, where its constituent part, i.e., earthing current $I_{E}$, determines the properties of the earthing-electrode voltage.

Impedance $Z_{R}=\left|Z_{R}\right| \mathrm{e}^{j \varphi} R$ is dependent on the earth-return path configuration in particular lines of the MV network. The impedance of the earth-return path of a given line is dependent on its length, and whether it is cable or overhead. Figures 3 and 4 illustrate the dependence of module $\left|Z_{R}\right|$ and argument $\varphi_{R}$ of the earth-return path impedance of the selected lines on their length $L$. These dependencies were obtained using the program EMPT-ATP for MV/LV substations placed every $250 \mathrm{~m}$ along the line. It was also assumed that the resistances $R_{B}$ (Figure 2) of these substations were connected to the analyzed earth-return path.

As far as non-effectively earthed MV networks are concerned, there is a difference in principle between the return paths of overhead and cable lines. This is illustrated in Figure 3, which presents the characteristics of earth-return impedance for a $15 \mathrm{kV}$ overhead line (Figure $3 a, b$ ) and a three single-core cables line with rated voltage $12 / 20 \mathrm{kV}$ (Figure 3c,d). In the overhead line, the earth-return path is the admittance (mainly susceptance) of the line. As a result, the $\left|Z_{R}\right|$ values of the analyzed line decrease with length by about $1 \mathrm{M} \Omega$ to about $50 \mathrm{k} \Omega$ (Figure 3a), and moreover, this impedance has a capacitive character (Figure $3 b$ ). The earth path impedance of a cable line is different from that of an overhead line, having differences in both character and value. Hence the conclusion that the earthreturn path is constituted by the metallic sheaths of cables, isolated from earth, to which the resistances $R_{B}$ are connected. Consequently, the values of $\left|Z_{R}\right|$ (Figure 3c) are several orders of magnitude lower than those in the overhead lines, and have an inductive character (Figure 3d). Unlike the overhead lines, the earth-return paths' impedance in cable lines strongly depends on resistance $R_{B}$ (Figure 3c). 


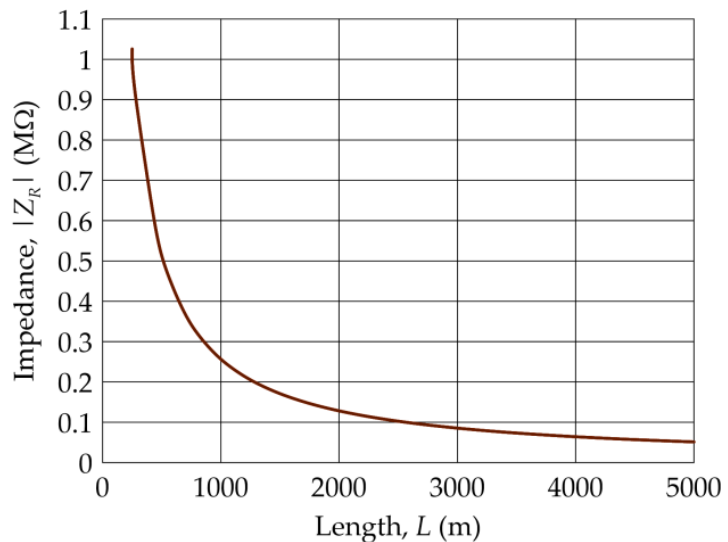

(a)

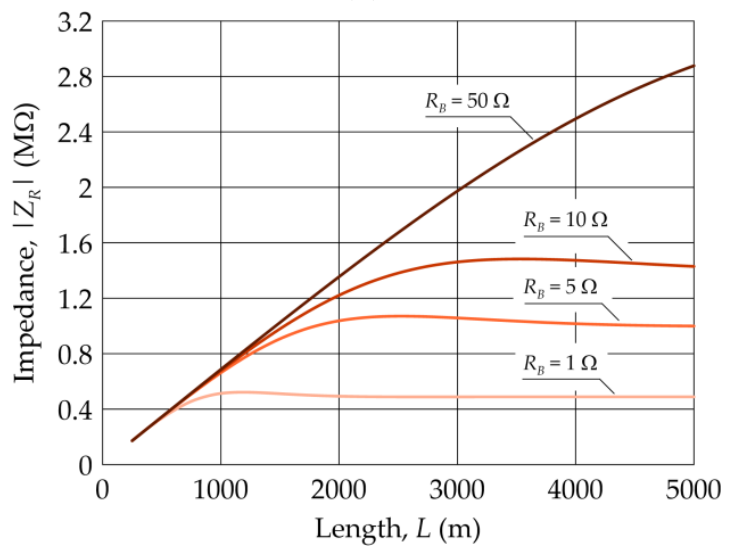

(c)

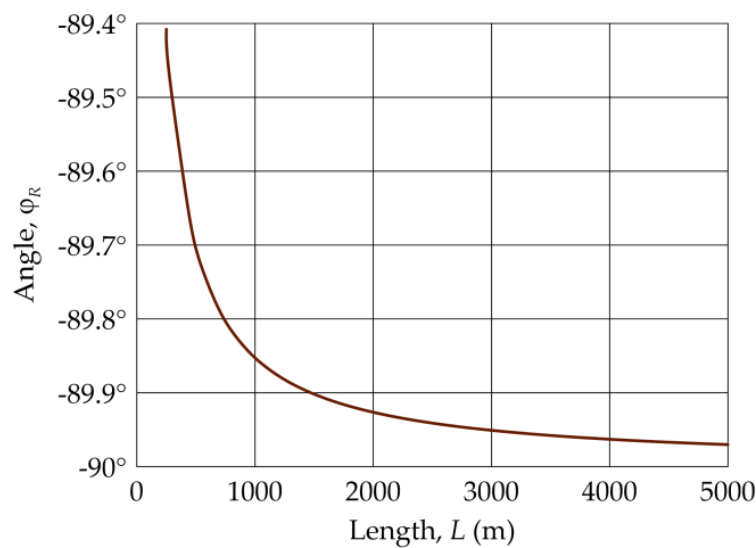

(b)

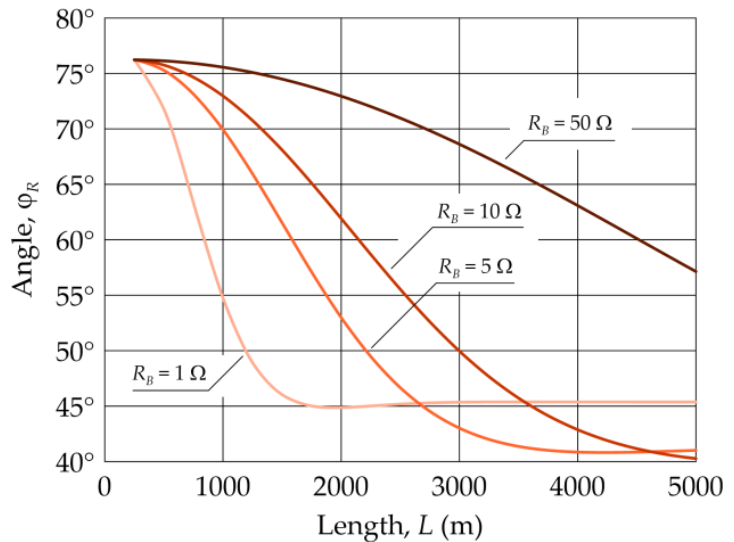

(d)

Figure 3. Dependence of module $\left|Z_{R}\right|$ and argument $\varphi_{R}$ of earth-return impedance for selected lines as a function of their length $L:(\mathbf{a}, \mathbf{b}) 15 \mathrm{kV}$ overhead line; (c,d) three $12 / 20 \mathrm{kV}$ single-core cables.

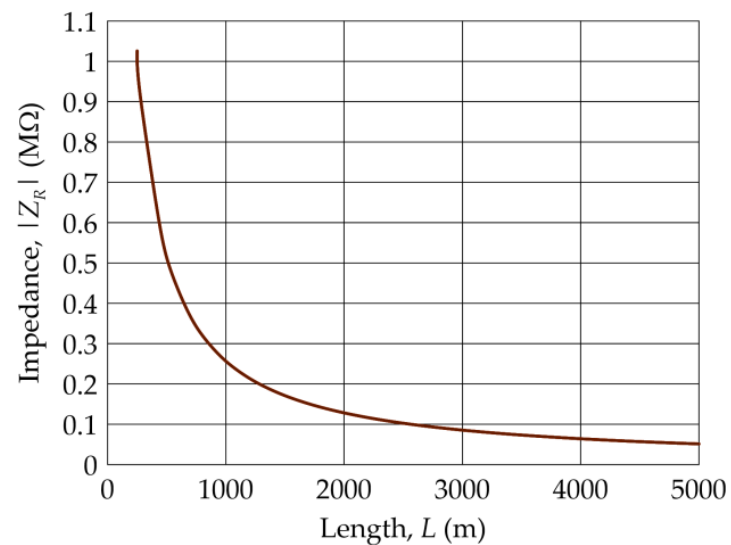

(a)

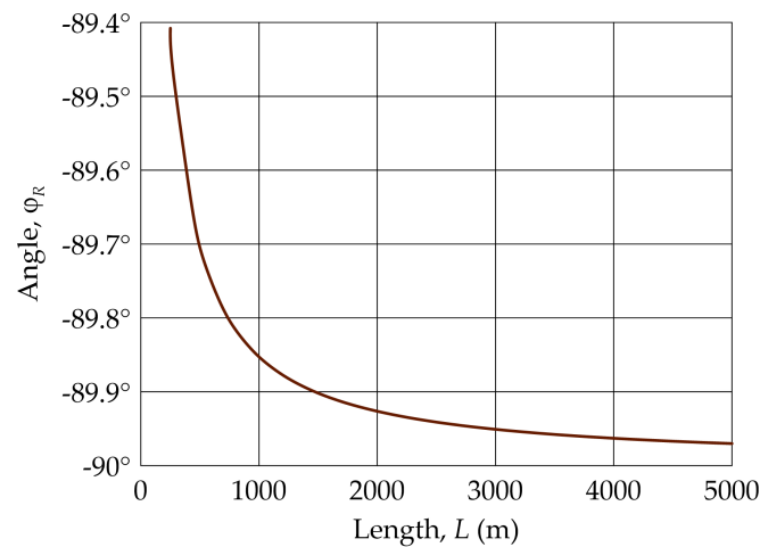

(b)

Figure 4. Dependence of module $\left|Z_{R}\right|(\mathbf{a})$ and argument $\varphi_{R}(\mathbf{b})$ of the earth-return path impedance as a function of the length $L$ of $8.7 / 15 \mathrm{kV}$ triple-core cable with a metallic sheath covered by a fibrous layer.

In triple-core cable lines, the return path is made up of metallic sheaths, which may be covered with a thermoplastic or a fibrous sheath. In the case of metallic sheaths covered by a thermoplastic layer, the properties of the earth-return path resemble those of single-core cables. For metallic sheaths covered by a fibrous layer, it can be assumed that the sheath is in direct contact with earth along the entire length of the cable. Although this does not 
result in significant differences in $\left|Z_{R}\right|$ values compared to single-core cables, the shapes of their impedance-length functions differ significantly. This is illustrated in Figure 4, which shows the characteristics of a triple-core cable with a metallic sheath covered by a fibrous layer with a rated voltage of $8.7 / 15 \mathrm{kV}$.

In real networks, the impedances of earth-return paths are random in nature, despite the fact that these paths are determined by a practically constant, predetermined network structure. The reason for this is the randomness of the resistance values $R_{B}$, which have an influence not only on impedance $Z_{R}$, but also on the equivalent earthing impedance $Z_{E}=Z_{R}|| R_{B}$ of a given substation (Figure 2). The randomness of resistance $R_{B}$ depends on several factors, although the random character of earthing resistance $R_{E}$ is decisive, as the atmospheric conditions greatly influence the geoelectric soil parameters [19-21]. Another important factor is resistance $R_{P E N}$, which is affected by atmospheric conditions as well as the evolution of the LV power grid structure, whereby there is an increase in the number of earthings with different resistances connected to the PEN.

For these reasons, the authors conducted analyses to determine the statistical properties of $R_{B}$ resistance. This study was based on a random sample of $N=2408$ measured $R_{B}$ resistance values taken from a general population of 261.2 thousand MV/LV substations located on soils with different geoelectric properties in Poland. These measurements were obtained under different atmospheric conditions in different months. The collected data were statistically analyzed using STATGRAPHICS software. Figure 5a shows the descriptive statistics of the random variable $R_{B}$ in the form of a box-and-whisker plot, and Figure $5 \mathrm{~b}$ shows the empirical and theoretical distribution of this variable.

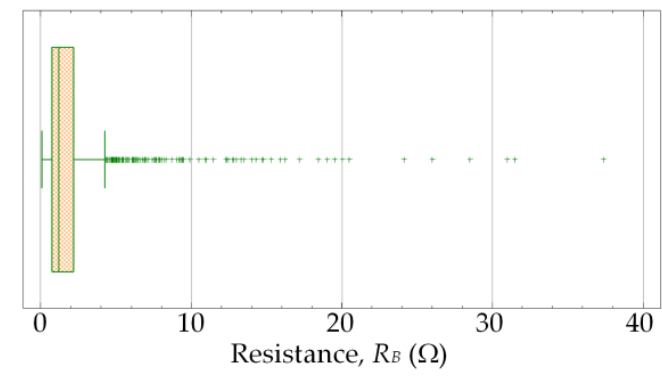

(a)

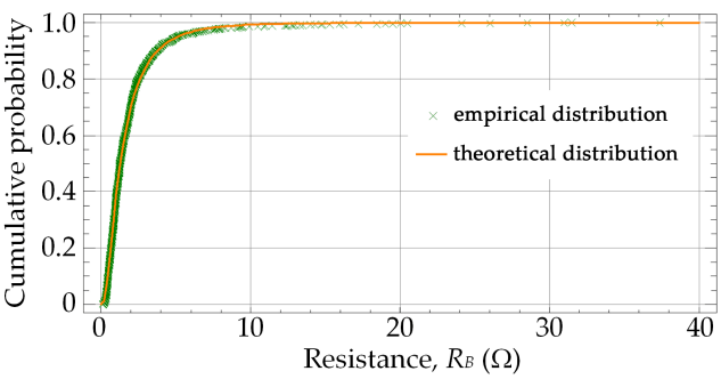

(b)

Figure 5. Box-and-whisker plot (a) and distribution (b) of a random variable $R_{B}$.

The statistical analysis revealed that the random variable $R_{B}$ can be described by a log-normal distribution with a probability density function:

$$
f\left(r_{B}\right)=\frac{1}{r_{B} \sqrt{2 \pi} \sigma} \exp \left[-\frac{1}{2}\left(\frac{\ln r_{B}-\mu}{\sigma}\right)^{2}\right],
$$

where $r_{B}$-value of random variable $R_{B} ; \mu, \sigma$-distribution parameters, $\mu=0.241, \sigma=0.845$ The Kolmogorov-Smirnov test showed that at a significance level $\alpha=0.05$, there is no reason to reject the hypothesis that the random variable $R_{B}$ conforms to Distribution (1).

The statistical model of $R_{B}$ resistance expressed by Distribution (1) served as the basis of the authors' original approach to evaluating electric shock hazard in MV/LV substations with resistance-earthed neutral points. The method proposed for this evaluation is presented in the next section.

\section{Method for Statistical Evaluation of Electric Shock Hazard in MV/LV Substations}

The subject of consideration is an MV electrical power network that supplies $M$ $\mathrm{MV} / \mathrm{LV}$ substations. The aim of this study is to determine the values of the earthingelectrode voltage:

$$
U_{E}(i, j), i=1, \ldots, M j=1, \ldots, N
$$


where $N$ is the number of random simulations of single line-to-earth faults at the $i$-th substation. In each simulation, the $R_{B}$ resistance value (Figure 2) is randomly selected from the log-normal Distribution (1), and the value of fault resistance at the $R_{F}$ fault location is determined using the Weibull distribution [22].

$$
f\left(r_{F}\right)=\lambda \beta r_{F}^{\beta-1} \exp \left(-\lambda r_{F}^{\beta}\right), r_{F}>0
$$

where $r_{F}$-value of random variable $R_{F} ; \lambda, \beta$-distribution parameters, $\lambda=0.002, \beta=1.5$.

On the basis of the simulations, $M$ random samples of earthing-electrode voltage $U_{E}$, each of size $N$, are obtained. These samples are subjected to statistical analysis. First, descriptive statistics are produced in the form of $M$ box-and-whisker plots of earthingelectrode voltage $U_{E}$ for individual MV/LV substations. These plots are then classified into three groups, A, B, and C (Figure 6), on the basis of the position of the plot with respect to the permissible $U_{E p}$ voltage levels, depending on the short-circuit duration.

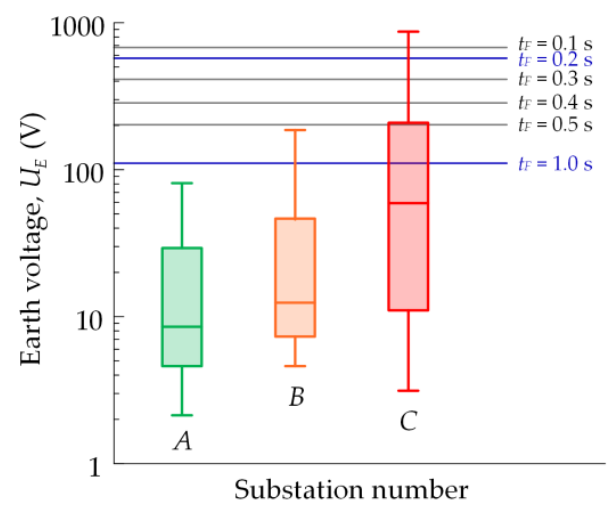

Figure 6. Types of box-and-whisker diagrams of earthing-electrode voltage at MV/LV substations, with permissible voltage levels indicated $U_{E p}=f\left(t_{F}\right)$.

In the substations, where the earth electrodes of medium- and low-voltage parts are interconnected (Figure 2), the values of earthing-electrode voltage $U_{E}$, which depend on the time $t_{F}$ of earth fault duration, are used to assess electric shock hazard [16,17]. The permissible $U_{E p}$ values of these voltages, according to IEC standards [23], are presented in Figure 7, approximated by a sixth-degree polynomial function over the time interval $0.1 \mathrm{~s} \leq t_{F} \leq 1.0 \mathrm{~s}$.

Group A includes all the substations in which the highest values of the random samples were lower than the permissible earthing-electrode voltage for the fault duration $t_{F}=1 \mathrm{~s}$ (the time $t_{F}=1 \mathrm{~s}$ was assumed a priori as the maximum fault current interruption time in the MV network). This means that in those substations where the earth-fault protection is set for shorter than $1 \mathrm{~s}$, shock safety is ensured, irrespective of the earth resistance value at those stations.

Group B includes all of the substations in which the highest values of the random samples were greater than the permissible earthing-electrode voltage for the fault duration $t_{F}=1 \mathrm{~s}$, but simultaneously smaller than the permissible earthing-electrode voltage for the fault duration $t_{F}=0.2 \mathrm{~s}$ (the time $t_{F}=0.2 \mathrm{~s}$ was assumed as the minimum obtainable fault current interruption time in the MV network). This means that electric shock safety can be ensured when the interruption time of earth-fault protection is properly set within a time interval of $0.2-1 \mathrm{~s}$, regardless of the ground resistance value of the substation. 


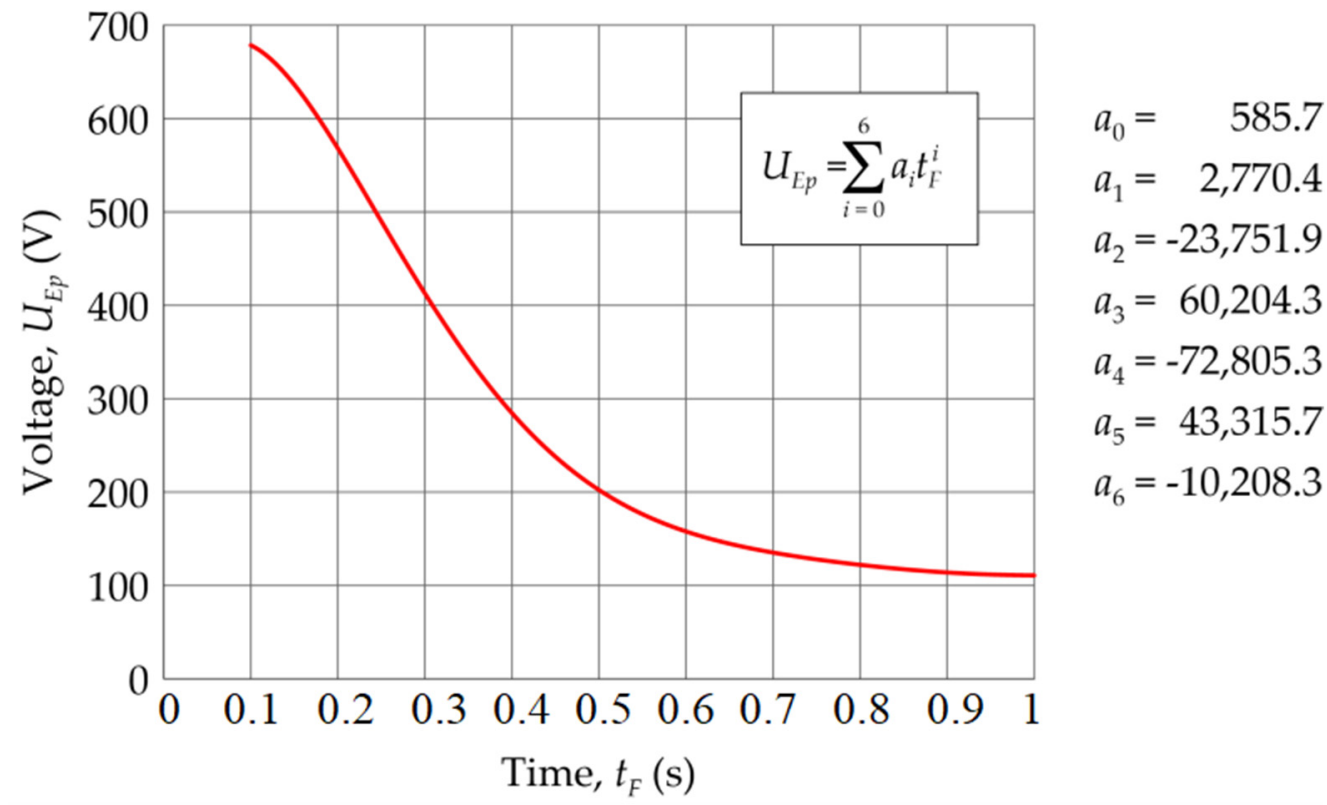

Figure 7. Permissible values of $U_{E p}$ earthing-electrode voltage in MV/LV substations as a function of earth fault duration $t_{F}$ based on the IEC standard (prepared on the basis [23]).

Group C includes all substations in which the highest values of the random samples were greater than the permissible earthing-electrode voltage for the earth fault duration $t_{F}=0.2 \mathrm{~s}$. This means that shock hazards can occur in these substations, the risk of which depends on their earth resistance. Therefore, a further statistical analysis is carried out for the substations in group $C$ to determine the dependence of this risk on the fault interruption time. In the first step of this analysis, the $F\left(u_{E}\right)$ distribution functions of the earth-electrode voltages $U_{E}$ are estimated and verified:

$$
F\left(u_{E}\right)=P\left(U_{E} \leq u_{E}\right), U_{E} \geq 0,
$$

on the basis of which the probability curves $G\left(u_{E}\right)$ for exceeding the earthing-electrode voltage $U_{E}$ are determined (Figure 8 ):

$$
G\left(u_{E}\right)=1-F\left(u_{E}\right)=P\left(U_{E}>u_{E}\right), U_{E} \geq 0,
$$

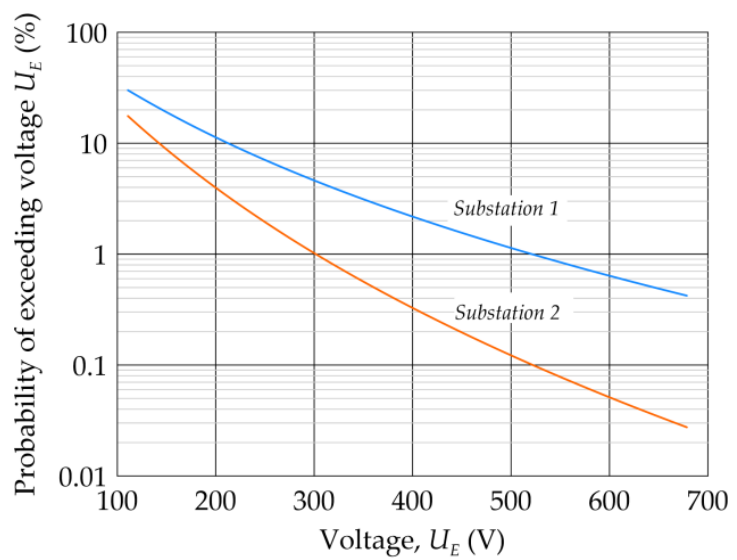

Figure 8. Exemplary probability of exceeding earthing-electrode voltage $U_{E}$ at type $C$ substations.

Based on the curves $G\left(u_{E}\right)$ and the relationship $U_{E p}=f\left(t_{F}\right)$ (Figure 7), the dependence of the probability of exceeding the permissible earthing-electrode voltage $U_{E p}$ on fault current interruption time $t_{F}$ (Figure 9 ) are established for the individual stations in group C. 


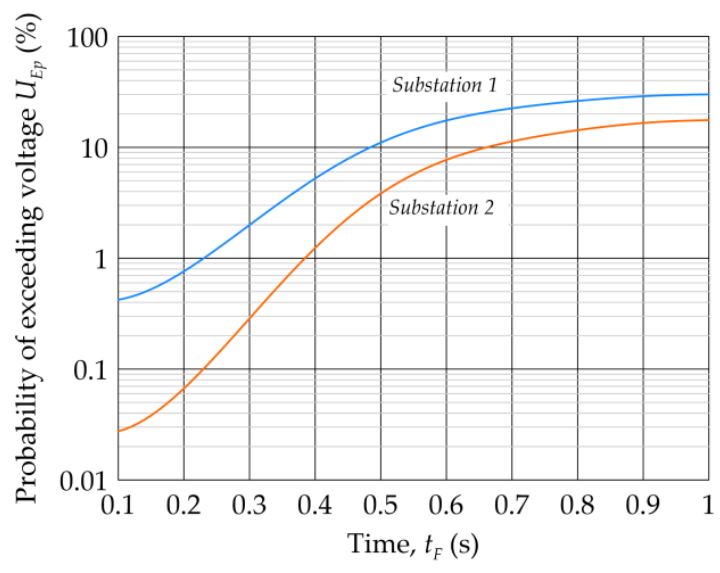

Figure 9. Exemplary probability of exceeding permissible earthing-electrode voltage $U_{E p}$ as a function of earth fault duration $t_{F}$.

The curves presented in Figure 9 constitute the basis for determining the longest earth fault protection interruption times in the $C$ group substations. For example: irrespective of the value of the earth resistance $R_{B}$, the probability of exceeding the $U_{E p}$ voltage at a level of $1 \%$ will be true for substation 1 when $t_{F}<0.23 \mathrm{~s}$ and for substation 2 when $t_{F}<0.38 \mathrm{~s}$. However, if the highest probability value is assumed at a level of $0.1 \%$, it is not possible to meet this condition by shortening the time $t_{F}$ at substation 1 . In this case, it is necessary to limit the $R_{B}$ earth resistance to the $R_{B \max }$ value in substation 1 , and consequently to truncate the distribution function (4). The $R_{B \max }$ value is determined by the correlation analysis of the random variables $U_{E}$ and $R_{B}$. The performed analyses revealed that the best fit of this correlation can be obtained either using a linear function:

$$
U_{E}=c_{1} R_{B}+c_{2}
$$

or an exponential function:

$$
U_{E}=c_{3}\left[1-\exp \left(c_{4} R_{B}\right)\right],
$$

where $c_{1}, c_{2}, c_{3}, c_{4}$-correlation parameters. Figure 10 shows an exemplary correlation of variables $U_{E}$ and $R_{B}$ for substation 1 , approximated using a linear function (6). This function shows that, for example, for the assumed resistance value $R_{B \max }=5 \Omega$, the voltage value obtained using the truncated Distribution (4) is $u_{E 0}=265.4 \mathrm{~V}$. Accordingly, for further analysis, the right-hand truncated distribution function (4) is assumed. It has the following form:

$$
H\left(u_{E}\right)=\left\{\begin{array}{cc}
P\left(U_{E} \leq u_{E} \mid U_{E} \leq u_{E 0}\right), & 0 \leq U_{E} \leq u_{E 0} \\
0, & U_{E}>u_{E 0}
\end{array},\right.
$$

Higher $u_{E 0}$ values also correspond to higher $R_{B \max }$ values, e.g., $u_{E 0}=528.9 \mathrm{~V}$ for $R_{B \max }=10 \Omega$, and $u_{E 0}=792.4 \mathrm{~V}$ for $R_{B m a}=15 \Omega$. As far as substation 1 is concerned, Figure 11 shows the probability curves $G\left(u_{E}\right)$ for exceeding the earthing-electrode voltage $U_{E}$ when the resistance $R_{B \max }$ is equal to $5 \Omega, 10 \Omega$, and $15 \Omega$, respectively. On the other hand, Figure 12 illustrates the corresponding probability dependencies for exceeding the permissible earthing-electrode voltage $U_{E p}$ for a given earth fault duration $t_{F}$ : 


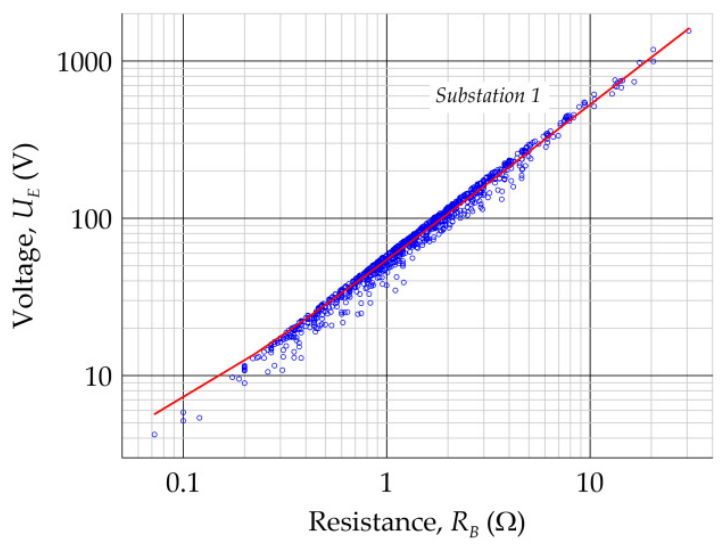

Figure 10. Exemplary correlation of random variables $U_{E}$ and $R_{B}$ at an $\mathrm{MV} / \mathrm{LV}$ substation.

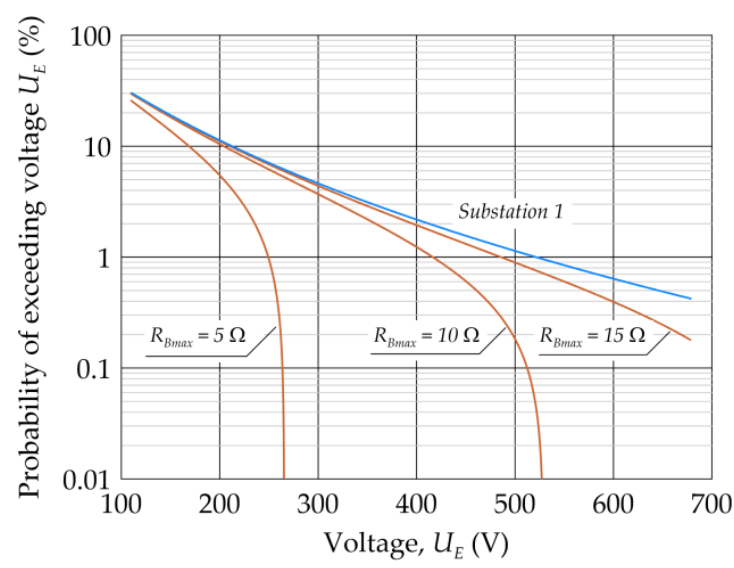

Figure 11. Probability of exceeding earthing-electrode voltage $U_{E}$ when resistance $R_{B}$ is limited to a maximum value of $R_{\text {Bmax }}$ equal to $5 \Omega, 10 \Omega$, and $15 \Omega$, respectively.

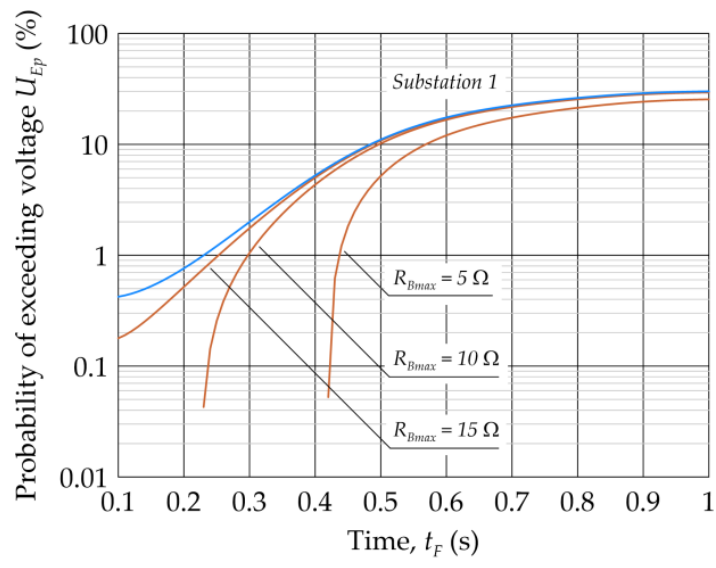

Figure 12. Dependence of the probability of exceeding permissible earthing-electrode voltage $U_{E p}$ on earth fault duration $t_{F}$ when limiting the resistance $R_{B}$ to maximum values $R_{B \max }$ equal to $5 \Omega, 10 \Omega$, and $15 \Omega$, respectively.

The curves presented in Figure 12 provide the basis for determining the longest interruption times for the earth-fault protection at substation 1 when limiting the maximum value of resistance $R_{B}$. For instance, if the maximum value of the probability of exceeding the permissible earthing-electrode voltage $U_{E p}$ is assumed to be $0.1 \%$, then this condition may be met with protection interruption times at substation of $1 t_{F}<0.42 \mathrm{~s}$ for $R_{B \max }=5 \Omega$, or $t_{F}<0.24 \mathrm{~s}$ for $R_{B \max }=10 \Omega$. 
The method presented above for the statistical evaluation of electric shock hazard in $\mathrm{MV} / \mathrm{LV}$ substations may serve as a basis for selecting the means of neutral point earthing in MV networks, and selecting the settings for the earth fault protection in networks using any earthing method. This method will be applied for the analysis of a real $15 \mathrm{kV}$ network operating with an isolated neutral point, as discussed in the following chapter, with special emphasis on the possibility of earthing the neutral point of this network using a resistor.

\section{Exemplary Application of Method-Analysis of a Real 15 kV Network}

The subject of this research was an actual $15 \mathrm{kV}$ cable-overhead network, the system diagram of which is shown in Figure 13. This network is supplied by a $110 \mathrm{kV}$ system through a 16 MVA transformer. In the $15 \mathrm{kV}$ switchgear, there are feeder bays marked as 01-04, supplying 44 substations with a nominal voltage of $15 / 0.4 \mathrm{kV}$, one auxiliary transformer (bay 05) with a ZNyn11 15.75/0.42 kV earthing transformer, and a voltage measuring bay (bay 06). The data of the analyzed network are presented in Table 1.

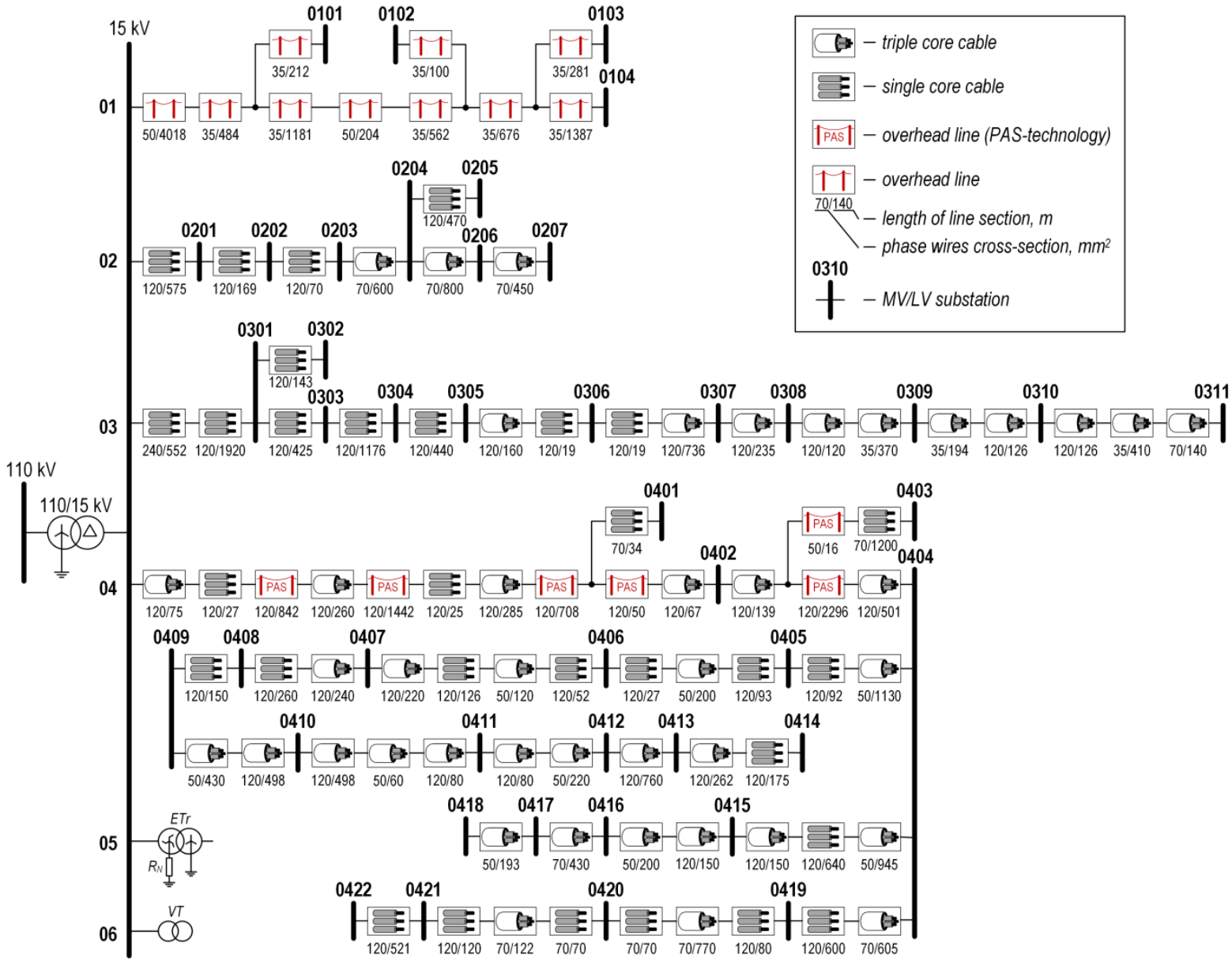

Figure 13. Diagram of the analyzed $15 \mathrm{kV}$ cable-overhead network.

Table 1. Data of the analyzed $15 \mathrm{kV}$ network.

\begin{tabular}{ccccc}
\hline Bay No. & $\begin{array}{c}\text { Length of Overhead } \\
\text { Lines [m] }\end{array}$ & $\begin{array}{c}\text { Length of Cable } \\
\text { Lines [m] }\end{array}$ & $\begin{array}{c}\text { Charging } \\
\text { Current [A] }\end{array}$ & $\begin{array}{c}\text { Number of Supplied } \\
\mathbf{1 5 / 0 . 4} \text { kV Substations }\end{array}$ \\
\hline 01 & 9105 & - & 0.24 & 4 \\
02 & - & 3134 & 2.32 & 7 \\
03 & - & 7311 & 5.59 & 11 \\
04 & 5352 & 14,052 & 11.01 & 22 \\
\hline Total & 14,457 & 24,497 & 19.16 & 44 \\
\hline
\end{tabular}


The analyzed $15 \mathrm{kV}$ network is currently operating with an isolated neutral point. The purpose of the study was to analyze the effect on electric shock hazard of changing the neutral point earthing method from isolated to resistance-earthed. This analysis consisted of determining the longest permissible fault current interruption times for line protection devices installed in bays $01-04$ of the $15 \mathrm{kV}$ switchgear and the maximum resistance of the $15 / 0.4 \mathrm{kV}$ substation earthing electrodes after changing the neutral point earthing method. This research was conducted using the method presented in Section 3.

Figure 14a shows the box-and-whisker diagrams of the earthing-electrode voltage $U_{E}$ in the $15 / 0.4 \mathrm{kV}$ substations for the present state of network operation (isolated neutral point), in which the single line-to-earth fault current $I_{F}=19.16 \mathrm{~A}$. It can be seen that three substations, numbered 0401, 0402, 0403, which are fed from bay 04, belong to group B. On the other hand, all substations fed from bay 01 belong to group $C$. The remaining substations qualify as belonging to group A. Figure $14 \mathrm{~b}$ shows analogous diagrams, but for a resistance-earthed neutral point $R_{N}=43.3 \Omega$, forcing a single line-to-earth fault current with an assumed value of $I_{F}=200$ A. This almost tenfold growth of the earth fault current increases the electric shock hazard. This is true for the previously mentioned substations, as well as substation 0207 (group B) and substation 0311 (group B). It should also be noted that with the neutral point operation method, substations 0401 and 0403 belong to group $C$. Figure $14 \mathrm{c}$ shows the diagrams for a resistance-earthed neutral point $R_{N}=17.3 \Omega$, forcing a single line-to-earth fault current with an assumed value of $I_{F}=500 \mathrm{~A}$. The neutral point earthing method further increases the electric shock hazard and changes the classification of substation 0402 from group B to group C. Moreover, it expands group B with substations 0205, 0206, 0310, 0404-0406, and 0413-0422.

Figure 15 presents the dependence of the probability of exceeding the permissible earthing-electrode voltage $U_{E p}$ on the earth fault duration $t_{F}$ in substations belonging to groups $\mathrm{B}$ and $\mathrm{C}$. These dependences serve as the basis for determining the longest acceptable fault interruption times for the earth fault protection devices installed in bays 01-04 of the $15 \mathrm{kV}$ switchgear. In the isolated neutral point network (Figure 15a), the time $t_{F}$ in bay 01 is determined by substation 0104 , with the simultaneous limitation $R_{B \max }=10 \Omega$ in substations 0101, 0102, 0103 and 0104, whereas in bay 04, the time $t_{F}$ is determined by substation 0401.

In the resistance-earthed neutral point network with $R_{N}=43.3 \Omega$ and a fault current of 200 A (Figure 15b), the following substations determine the time $t_{F}$ : bay 01 - substation 0102 $\left(R_{\text {Bmax }}=5 \Omega\right)$; bay 02-substation 0207; bay 03—substation 0311; bay 04—substation 0401 $\left(R_{\text {Bmax }}=5 \Omega\right)$. In the resistance-earthed neutral point network with $R_{N}=17.3 \Omega$ and a fault current of 500 A (Figure 15c), the following substations determine the choice of $t_{F}$ times: bay 01-substation $0101\left(R_{B \max }=3 \Omega\right.$; bay 02-substation 0207; bay 03-substation 0311; bay 04 -substation $0401\left(R_{B \max }=3 \Omega\right)$.

This research showed that changing the method in which the network neutral point is earthed has a very significant impact on the values of earthing-electrode voltage in the analyzed substations. This increases the shock hazard level, and thus the number of substations classified as having higher earthing-electrode voltages.

Based on the results presented in Figures 14 and 15, Table 2 shows the determined values of time $t_{\text {Fmax }}$ and resistance $R_{B \max }$ in the analyzed $15 \mathrm{kV}$ network with an assumed probability of exceeding the permissible earthing-electrode voltage of $1.0 \%$ and $0.1 \%$.

The presented analysis shows that it is possible to change the neutral point earthing method in the studied network from isolated to resistance earthed. However, in order to reduce the electric shock hazard, the conditions listed in Table 2 must be met. These conditions specify the remedies that can be applied to reduce the risk of electric shock to the acceptable level defined in the assumption. These measures include: shortening the fault current interruption times in selected switchgear bays, or reducing the earthing electrode resistance in selected MV/LV substations to the calculated values. 


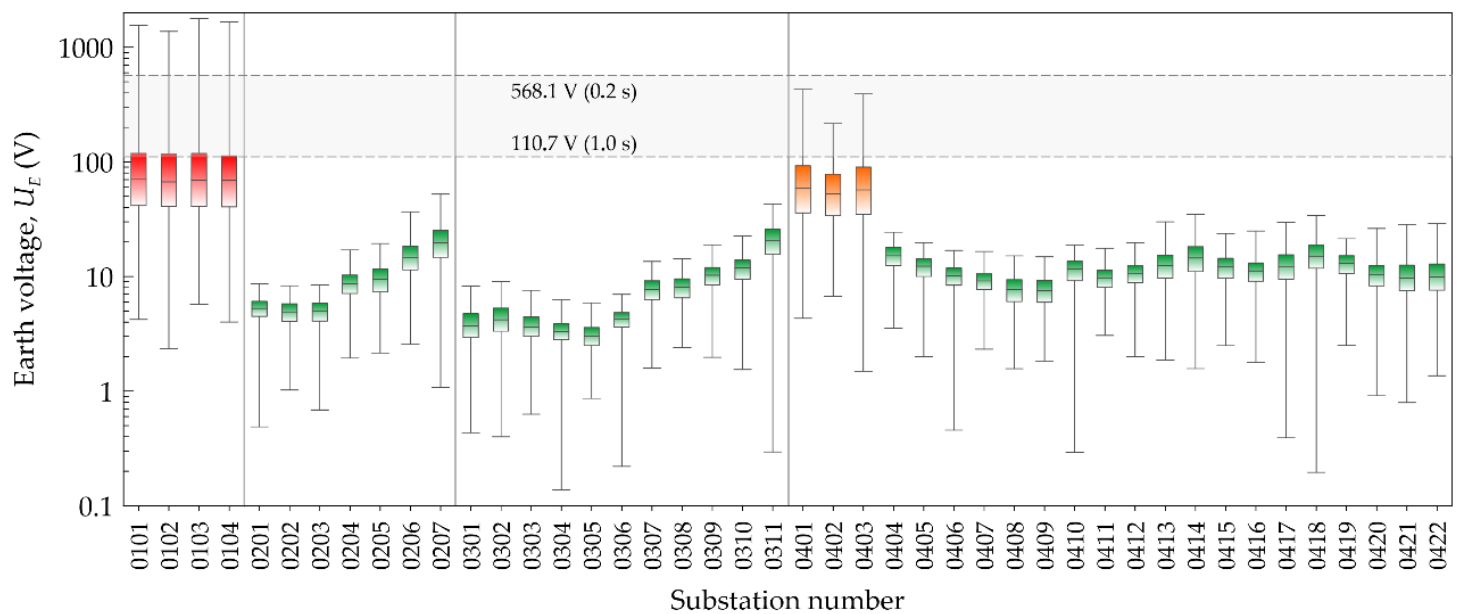

(a)

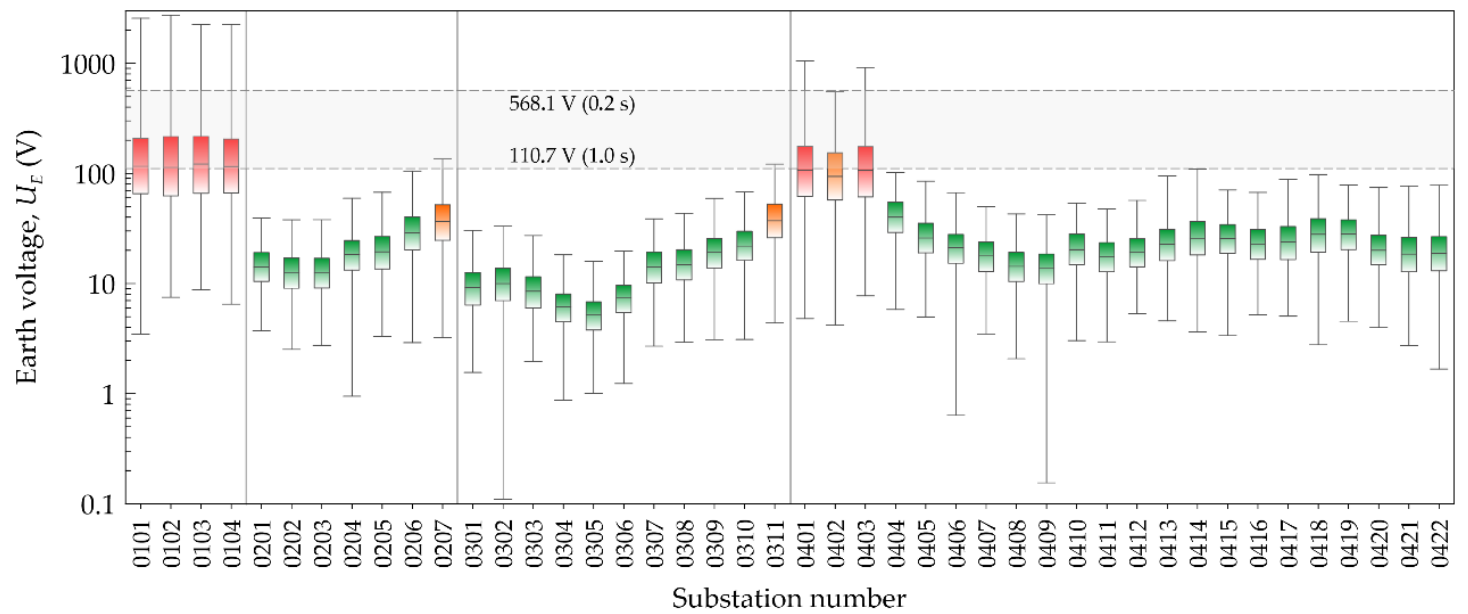

(b)

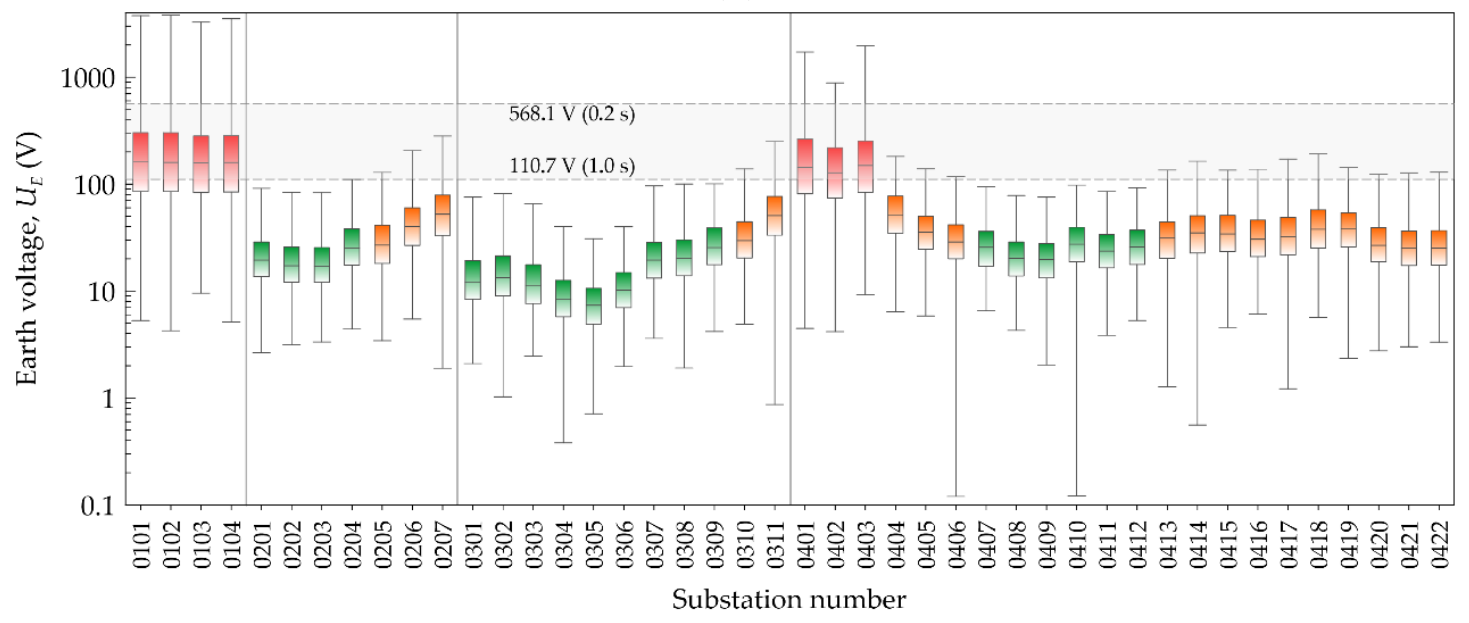

(c)

Figure 14. Box-and-whisker plots of earthing-electrode voltage $U_{E}$ for the analyzed neutral point earthing method in the $15 \mathrm{kV}$ network: (a) isolated neutral point; (b) resistance-earthed point $R_{N}=43.3 \Omega$ with an earth fault current of $200 \mathrm{~A} ;(\mathbf{c})$ resistance-earthed point $R_{N}=17.3 \Omega$ with an earth fault current of $500 \mathrm{~A}$. 


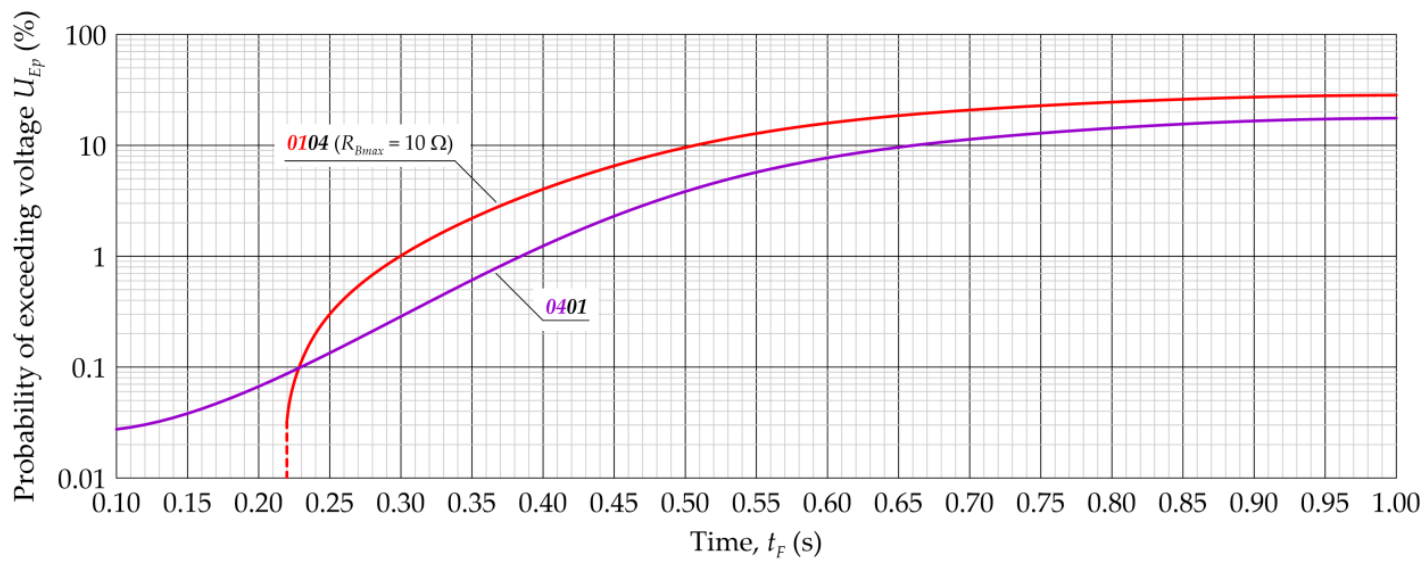

(a)

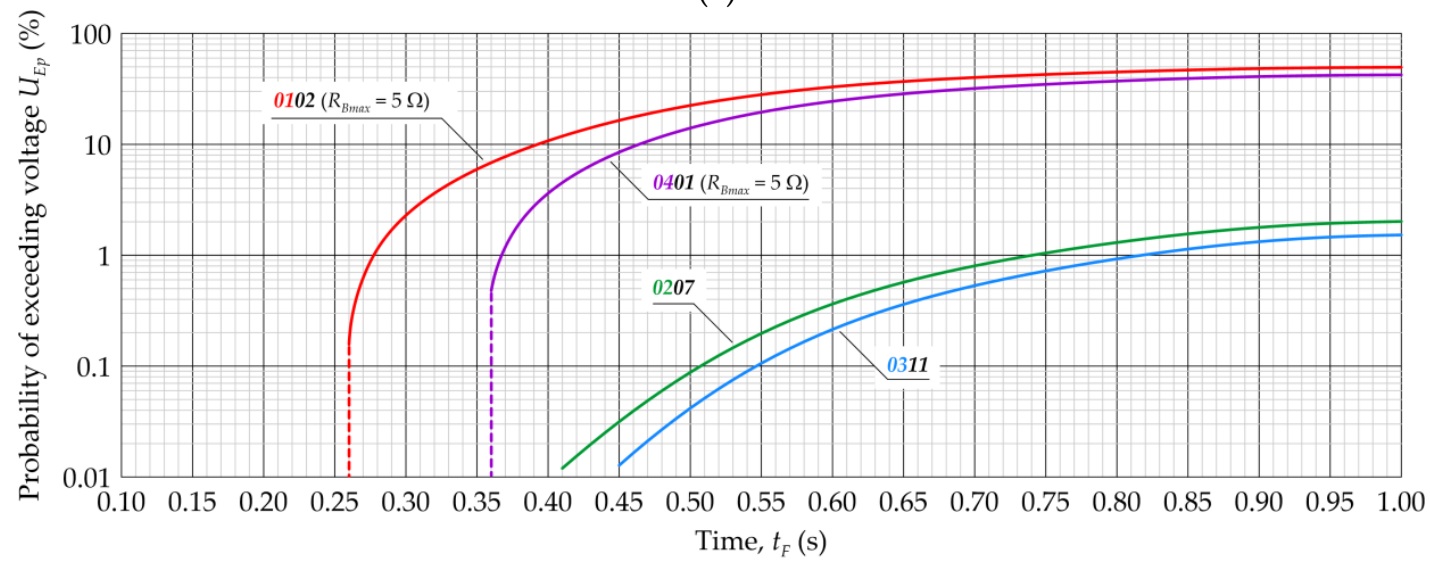

(b)

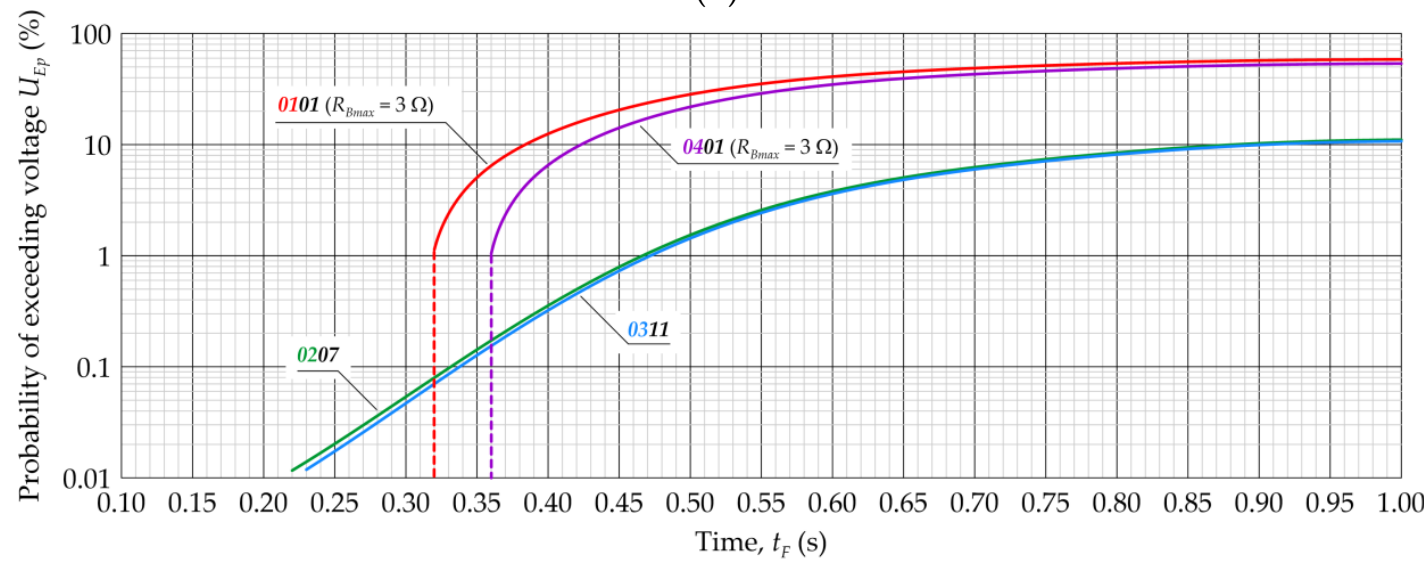

(c)

Figure 15. Dependence diagrams of the probability of exceeding the permissible earthing-electrode voltage $U_{E p}$ on the earth fault duration $t_{F}$ for the considered method of neutral point operation in the $15 \mathrm{kV}$ network: (a) isolated neutral point; (b) resistance-earthed point $R_{N}=43.3 \Omega$ with an earth fault current of $200 \mathrm{~A}$; (c) resistance-earthed neutral point $R_{N}=17.3 \Omega$ with an earth fault current of $500 \mathrm{~A}$. 
Table 2. Determined values of time $t_{\text {Fmax }}$ and resistance $R_{B m a x}$ in the analyzed $15 \mathrm{kV}$ network with assumed probability of exceeding permissible earthing-electrode voltage.

\begin{tabular}{|c|c|c|c|c|c|c|c|}
\hline \multirow{3}{*}{ Bay } & \multirow{3}{*}{ Probability } & \multicolumn{6}{|c|}{ Neutral Point } \\
\hline & & \multicolumn{2}{|c|}{ Isolated } & \multicolumn{2}{|c|}{$R_{N}=43.3(200 \mathrm{~A})$} & \multicolumn{2}{|c|}{$R_{N}=17.3(500 \mathrm{~A})$} \\
\hline & & $t_{F \max }(\mathrm{s})$ & $R_{B \max }(\Omega)$ & $t_{F \max }(\mathrm{s})$ & $R_{B \max }(\Omega)$ & $t_{F \max }(\mathrm{s})$ & $R_{B \max }(\Omega)$ \\
\hline \multirow{2}{*}{01} & $1.0 \%$ & 0.30 & $10^{(1)}$ & 0.25 & $5^{(1)}$ & 0.30 & $3^{(1)}$ \\
\hline & $0.1 \%$ & 0.20 & $10^{(1)}$ & 0.25 & $5^{(1)}$ & 0.30 & $3^{(1)}$ \\
\hline \multirow[b]{2}{*}{02} & $1.0 \%$ & 1.0 & $\mathrm{n} / \mathrm{a}$ & 0.70 & $\mathrm{n} / \mathrm{a}$ & 0.45 & $\mathrm{n} / \mathrm{a}$ \\
\hline & $0.1 \%$ & 1.0 & $\mathrm{n} / \mathrm{a}$ & 0.50 & $\mathrm{n} / \mathrm{a}$ & 0.30 & $\mathrm{n} / \mathrm{a}$ \\
\hline \multirow{2}{*}{03} & $1.0 \%$ & 1.0 & $\mathrm{n} / \mathrm{a}$ & 0.80 & $\mathrm{n} / \mathrm{a}$ & 0.45 & $\mathrm{n} / \mathrm{a}$ \\
\hline & $0.1 \%$ & 1.0 & $\mathrm{n} / \mathrm{a}$ & 0.50 & $\mathrm{n} / \mathrm{a}$ & 0.30 & $\mathrm{n} / \mathrm{a}$ \\
\hline \multirow{2}{*}{04} & $1.0 \%$ & 0.35 & $\mathrm{n} / \mathrm{a}$ & 0.35 & $5^{(2)}$ & 0.35 & $3^{(3)}$ \\
\hline & $0.1 \%$ & 0.20 & $\mathrm{n} / \mathrm{a}$ & 0.35 & $5^{(2)}$ & 0.35 & $3^{(3)}$ \\
\hline
\end{tabular}

(1) for stations $0101,0102,0103,0104,{ }^{(2)}$ for stations 0401, 0403, ${ }^{(3)}$ for stations $0401,0402,0403$.

\section{Concluding Remarks}

The choice of a neutral point earthing method for a power network is a complex and multi-faceted issue. The main criterion for this selection is the level of shock hazard accompanying earth faults. This mainly applies to networks with non-effectively earthed neutral points. The use of deterministic methods in practice requires the assumption of values of many parameters, especially the earthing electrode resistances of $\mathrm{MV} / \mathrm{LV}$ substations. The actual earthing electrode resistances vary significantly in time; therefore, deterministic approaches to the evaluation of the shock hazard imply the necessity of assuming large safety factors. Accordingly, a statistical approach was used to assess the shock hazard in this study. In the course of the research, the authors proposed a method, the additional value of which is the use of a probabilistic model of substation earthing resistance, developed on the basis of real measurement data. The proposed method is universal and can be applied regardless of the power grid structure.

The applicability of the developed method was demonstrated by analyzing the effect on shock hazard of changing the neutral point earthing method from isolated to resistance earthed. Calculations were performed for a real medium-voltage network model. This example demonstrated that the method enabled the classification of individual MV/LV substations into three groups according to the level of shock hazard. The research showed that changing the method by which the network neutral point is earthed has a very significant impact on the values of earthing-electrode voltages in the analyzed substations. This increases the shock hazard level, and thus the number of substations classified as having higher earthing-electrode voltages. The developed method can be used to determine the risk of exceeding the permissible value of shock hazard in the analyzed substations. On this basis, it is possible to determine remedial measures might be applied to reduce the risk of electric shock to the assumed acceptable level. These measures include: shortening the fault current interruption times in selected switchgear bays, and reducing the earthing electrode resistance in selected MV/LV substations to the calculated values.

The method presented in this paper is also applicable for selecting neutral point earthing methods in electrical power networks both at the design stage and when changes to these methods are being considered in existing networks. Moreover, the authors plan in further studies to use the developed method to analyze shock hazard in MV networks resulting from the transfer of voltage through the earthing of HV/MV substations during faults in HV networks. 


\begin{abstract}
Author Contributions: Conceptualization, W.N. and R.T.; methodology, W.N. and R.T.; software, W.N., R.T., W.S. and J.K.; validation, W.N., R.T. and W.S.; formal analysis, W.N. and R.T.; investigation, J.K. and R.T.; writing-original draft preparation, W.N., R.T., W.S. and J.K.; writing-review and editing, R.T.; visualization, W.N. and R.T.; supervision, R.T. All authors have read and agreed to the published version of the manuscript.
\end{abstract}

Funding: This research received no external funding.

Institutional Review Board Statement: Not applicable.

Informed Consent Statement: Not applicable.

Data Availability Statement: The study did not report any data.

Conflicts of Interest: The authors declare no conflict of interest.

\title{
References
}

1. El-Sherif, N.; Kennedy, S.P. A design guide to neutral grounding of industrial power systems. In Proceedings of the 2017 Petroleum and Chemical Industry Technical Conference (PCIC), Calgary, AB, Canada, 18-20 September 2017. [CrossRef]

2. IEEE Guide for the Application of Neutral Grounding in Electrical Utility Systems_Part I: Introduction; IEEE: Piscataway Township, NJ, USA, 2016.

3. Olejnik, B. Adaptive Zero-Sequence Overcurrent Criterion for Earth Fault Detection for Fault Current Passage Indicators in Resistor Grounded Medium Voltage Networks. IEEE Access. 2021, 9, 63952-63965. [CrossRef]

4. Wahlroos, A.; Altonen, J.; Xavier, J. Can compensated networks be an alternate solution to reduce the risk of ground faults causing forest fires? In Proceedings of the 2021 74th Conference for Protective Relay Engineers (CPRE), College Station, TX, USA, 28-31 March 2021. [CrossRef]

5. Marin, I.; Ursu, D.; Ciontu, M.; Mircea, P.-M.; Mircea, I.; Buzatu, G.-C. Study of Overvoltages at the Extinguishing Coil Disconnection from Medium Voltage Networks in Stabilized Earthing Regime. In Proceedings of the 2021 International Conference on Applied and Theoretical Electricity (ICATE), Craiova, Romania, 27-29 May 2021. [CrossRef]

6. Vasilyeva, A.Y.; Shirkovets, A.I.; Telegin, A.V.; Sarin, L.I.; Ilinykh, M.V. Transient processes at single phase-to-ground faults in combined grounded networks. In Proceedings of the 2011 3rd International Youth Conference on Energetics (IYCE), Leiria, Partugal, 7-9 July 2011.

7. Cerretti, A.; Gatta, F.M.; Geri, A.; Lauria, S.; Maccioni, M.; Valtorta, G. Temporary overvoltages due to ground faults in MV networks. In Proceedings of the 2009 IEEE Bucharest PowerTech, Bucharest, Romania, 28 June-2 July 2009. [CrossRef]

8. Dimopoulos, A.; Griffiths, H.; Harid, N.; Haddad, A.; Ainsley, A.; Mpofu, G. Probability surface distributions for application in grounding safety assessment. IEEE Trans. Power Deliv. 2012, 27, 1928-1936. [CrossRef]

9. Nahman, J. Assessment of the risk of fatal electric shocks inside a substation and in nearby exposed areas. IEEE Trans. Power Deliv. 1990, 5, 1794-1801. [CrossRef]

10. Colella, P.; Napoli, R.; Pons, E.; Tommasini, R.; Barresi, A.; Cafaro, G.; De Simone, A.; Di Silvestre, M.; Martirano, L.; Montegiglio, P.; et al. Currents Distribution During a Fault in an MV Network: Methods and Measurements. IEEE Trans. Ind. Appl. 2016, 52, 4585-4593. [CrossRef]

11. Pons, E.; Colella, P.; Napoli, R.; Tommasini, R. Impact of MV Ground Fault Current Distribution on Global Earthing Systems IEEE Trans. Ind. Appl. 2015, 51, 4961-4968. [CrossRef]

12. Campoccia, A.; Sanseverino, E.; Zizzo, G. Analysis of Interconnected Earthing Systems of MV/LV Substations in Urban Areas. In Proceedings of the 2008 43rd International Universities Power Engineering Conference, Padua, Italy, 1-4 September 2008. [CrossRef]

13. Colella, P.; Pons, E.; Tommasini, R. A Comparative Review of the Methodologies to Identify a Global Earthing System. IEEE Trans. Ind. Appl. 2017, 53, 3260-3267. [CrossRef]

14. Di Silvestre, M.; Dusonchet, L.; Favuzza, S.; Mangione, S.; Mineo, L.; Mitolo, M.; Sanseverino, E.; Zizzo, G. On the Interconnections of HV-MV Stations to Global Grounding Systems. IEEE Trans. Ind. Appl. 2019, 55, 1126-1134. [CrossRef]

15. Campoccia, A.; Mineo, L.; Zizzo, G. A Method to Evaluate Voltages to Earth during an Earth Fault in an HV Network in a System of Interconnected Earth Electrodes of MV/LV Substations. IEEE Trans. Power Deliv. 2008, 23, 1763-1772. [CrossRef]

16. Bastian, M.B.; Carman, W.D.; Woodhouse, D.J. A network asset based probabilistic model of ground potential rise and touch voltage hazard profiles at MV substations. In Proceedings of the IEEE, 2016 Down to Earth Conference (DTEC), Hunter Valley, Australia, 1-4 September 2016. [CrossRef]

17. Griffiths, I.; Woodhouse, D.; Palmer, S. Use of finite probabalistic modelling to establish earthing hazard limits. In Proceedings of the IET, 22nd International Conference and Exhibition on Electricity Distribution (CIRED 2013), Stockholm, Sweden, 10-13 June 2013. [CrossRef]

18. Dimopoulos, A.; Griffiths, H.; Harid, N.; Haddad, A.; Ainsley, A.; Guo, D.; Mpofu, G. Proposal for Probabilistic Risk Assessment in Grounding Systems and Its Application to Transmission Substations. IEEE Trans. Power Deliv. 2012, 27, 2219-2226. [CrossRef] 
19. Dawalibi, F.P.; Ma, J.; Southey, R.D. Behaviour of grounding systems in multilayer soils: A parametric analysis. IEEE Trans. Power Deliv. 1994, 9, 334-342. [CrossRef]

20. He, J.; Zeng, R.; Gao, Y.; Tu, Y.; Sun, W.; Zou, J.; Guan, Z. Seasonal influences on safety of substation grounding system. IEEE Trans. Power Deliv. 2003, 18, 788-795. [CrossRef]

21. Razali, M.N.F.B.; Osman, S.B.A.b.S. Non-quantitative correlation of soil resistivity with some soil parameters. In Proceedings of the IEEE 2011 National Postgraduate Conference, Perak, Malaysia, 19-20 September 2011. [CrossRef]

22. Bernard, J.; Pahwa, A. Determination of the impacts of high impedance faults on protection of power distribution systems using a probabilistic model. Electr. Power Syst. Res. 1993, 28, 11-18. [CrossRef]

23. IEC 60364-4-44; Low-voltage Electricall Instalations. Part 4-44: Protection for Safety-Protection against Voltage Disturbances and Electromagnetic Disturbances. IEC: Geneva, Switzerland. 